\title{
NUMERICAL MODELLING OF DISPLACEMENT \\ PILE RESISTANCE IN SAND GROUND. \\ PART 1: SOIL PHYSICAL MODEL, \\ CALIBRATION OF MODEL PARAMETERS
}

\author{
VAIDAS MARTINKUS ${ }^{1}$, ARNOLDAS NORKUS ${ }^{2 *}$, \\ DŽIGITA NAGROCKIENE் ${ }^{3}$ \\ ${ }^{1}$ CSD Engineers, Vilnius, Lithuania \\ ${ }^{2}$ Laboratory of Geotechnics, Vilnius Gediminas Technical University, \\ Vilnius, Lithuania \\ ${ }^{3}$ Vilnius Gediminas Technical University, Vilnius, Lithuania \\ Received 26 February 2020; accepted 3 February 2021
}

\begin{abstract}
Accuracy of numerical modelling of ground resistance of the displacement pile highly depends on proper evaluation of its states: prior loading and its changes during the loading. Evaluation of initial ground stage, its subsequent changes caused by pile installation and, finally, evolution of the loaded pile resistance are the modelling stages that require validation with specialized test results performed under controlled laboratory conditions. Selection of the proper physical soil model and its parameters should be also done in accordance with the relevant soil tests results. The first paper briefly introduces testing results of a displacement pile prototype. Tests were conducted in the created sand deposit in the laboratory pit. Determining pile
\end{abstract}

\footnotetext{
* Corresponding author. E-mail: arnoldas.norkus@vgtu.lt
} 
resistance and ground stress-strain distribution in the vicinity of the pile allows selecting the physical model for the soil. Numerical calibration of the parameters for the physical model of the selected soil was performed. The second, following paper will introduce analyses of pile resistance. It involves creation of a discrete model and its parameters, numerical modelling of pile resistance against vertical load. The pile ground resistance modelling applying the physical model of the selected soil includes the following stages: evaluation at rest stage and assessment of residual effects of installation and displacement pile loading resistance. Numerical analyses results were validated with displacement pile prototype testing results.

Keywords: displacement pile, numerical calibration of soil parameters, sand, soil physical model.

\section{Introduction}

Analysis and design approaches for predicting the bearing resistance and deformation of a pile and pile group foundations are the issues raising continuous interest in engineering practice. Piles and piled structures are used in building and bridge construction, for stabilization of slopes and earth structures, in road engineering, when soil layers characterized by low bearing capacity and large deformability are shallow. Piles are often installed in piled embankments aiming to reduce surface settlement. For example, the fill above soft soils or organic layers is strengthened by using the load-transfer platform, supported from below by piles or pile groups. This construction allows reducing the stresses developed in soft soils. Hewlet \& Randolph (1988) introduced the arching method for piled embankments, proposing the relation for determining the vertical stress (load) transmitted to the pile cap; such investigations on design of piled embankments using the geosynthetic reinforcement for soil can also be mentioned in Love \& Milligan (2003); Raithel, Kirchner, \& Kempfert (2008). In all aforementioned and other complex engineered piled solutions the prediction of pile resistance is the key point in determining stress-strain distribution in the upper ground layers.

A large number of experimental, analytical and numerical investigations on prediction of pile and pile group foundation resistance have been performed up to know. Numerical modelling of ground behavior is a powerful tool for analyzing pile foundation resistance measures for various levels of pile loading. Unsever, Matsumoto, \& Ozkan (2015) presented an experimental and numerical investigation of piled raft performance of the pile group installed in dry sand. Hardening soil model (HSM) was employed in investigation for analysis using Plaxis 3D software. Basile (2015) presented the non-linear analysis of a vertically 
loaded piled raft using 3D boundary element solutions, having compared the method with other numerical techniques. The main emphasis was made on considering nonlinear soil response in pile foundation design. El-Garhy, Galil, \& Mari (2018) analyzed a flexible raft resting on granular soil over soft soil, presenting the results of parametric analysis of various factors. The research specifically considered the pile-soil-pile shear interaction effect for response measures of foundation; the results of numerical analyses using Plaxis 3D were compared with other known prediction methods and field measurements. Imseeh \& Alshibli (2018) presented a 3D finite element model for modelling load transmission effects of particle fracture. Modelling results showed good agreement with experiments in investigation.

However, the reliability of numerical analysis depends on many factors. Therefore, any proposed method or approach requires validation by relevant tests, minimizing the side factors.

Displacement pile (DP) generally is the most efficient pile type regarding its bearing resistance, as its installation strengthens load bearing capacity of the shaft and base. On the other hand, prediction of ground resistance of the loaded DP and their groups is rather difficult as it requires proper evaluation of soil effects - pile and soil-pile-soil and finally the pile-raft interaction (Norkus \& Martinkus, 2019). The developed analytical, empirical, semi-empirical methods, when they are validated by the relevant field tests or laboratory tests with larger scale DP prototypes, serve as rational alternatives for the geotechnical design. It should be emphasized that each method of pile foundation behavior analysis is developed under certain assumptions and restrictions. Application boundaries for the proposed model should be clearly defined, as pile resistance evolution depends on many factors, first and foremost on the pile type, pile slenderness and load type.

Evaluation of residual effects, i.e., determining the actual soil properties in the vicinity of the pile when installation load of displacement pile (DP) is removed, depends on proper evaluation of the initial (at rest) ground soil properties and the stress state. Prediction of loading resistance of the installed DP depends on the proper evaluation of the residual stress-strain state (SSS), relating it with the initial SSS of the ground. Comprehensive laboratory test data on the initial properties of the ground serve as a necessary data set for choosing the relevant physical model of the soil, employed for prediction of the DP resistance. The numerical modelling techniques and results presented in investigation are validated with the soil deposit testing and the DP resistance testing results. The DP test program included creation of a sand deposit in a large volume laboratory pit, performance of laboratory tests of deposit samples, DP installation and DP resistance tests and ground stress and displacement measurements.
Numerical Modelling of Displacement

Pile Resistance in Sand Ground. Part 1: Soil Physical Model, Calibration of Model Parameters 
The maximum DP load magnitude was chosen according to the ultimate limit state criterion of the pile, conforming to pile conditional settlement $s_{\mathrm{u}}=0.2 D$, where $D$ is pile diameter.

\section{Description of displacement pile test program}

Most models for pile resistance prediction were developed for the piles with higher slenderness $L / D \geq 20$ (where $L$ is pile length and $D$ is pile diameter). In many regions of East Europe, the layers of dense or overconsolidated soils are shallow. Short piles, i.e., of slenderness $L / D \approx 5-7$ are used on these soils. In case base resistance of such pile is greater than its shaft resistance, significant shaft resistance is mobilized near the pile base. Investigation of the bearing resistance for the short displacement pile (SDP) and their groups is performed at Vilnius Gediminas Technical University.

The SDP test program was realized at the Geotechnical Laboratory of Vilnius Gediminas Technical University. A special construction steel SDP prototype of $1.445 \mathrm{~m}$ length and $0.219 \mathrm{~m}$ diameter (slenderness $L / D=1.445 / 0.219=6.6$ ) was constructed to realize the program of pile resistance analysis by testing. The piles were tested in the laboratory pit of $5.0 \mathrm{~m}$ width, $7.8 \mathrm{~m}$ length and $4.5 \mathrm{~m}$ depth, filled by air-dry soil volume. The total soil volume of $2.5 \mathrm{~m}$ depth was dug out, after that it was filled anew with compacted soil layers. Evenly distributed medium coarse sand was used. The thickness of the newly created sand deposit was chosen according to the assumption made in Fleming, Weltman, Randolph, \& Elson (2009); Jardine, Chow, Overy \& Standing (2005); Lehane, Jardine, Bond, \& Frank (2005); and Schmertmann (1978), stating that the depth of the deformed ground below the pile base varies in the range of 1 to 5 pile diameters. Compaction of the sand deposit was performed with the aim to ensure stable properties up to $2.5 \mathrm{~m}$ depth from the ground surface. Below this level, a homogenous sand soil layer prepared previously was left unchanged. Soil compaction was performed by applying the single direction plate compactor. An optimal layer height of $0.15 \mathrm{~m}$ (17 layers for compacted volume height) was chosen according to the compacting capability of the employed compactor. Compaction quality was controlled by Dynamic Plate Load test, adopting the average dynamic deformation modulus $E_{\mathrm{d}}=22.90 \mathrm{MPa}$. In order to characterize the properties of the created silica sand deposit, routine soil laboratory tests (24 direct shear tests under constant vertical load, 3 oedometer and 3 consolidated triaxial tests) with 9 samplings at 3 ground levels (see 3 blue points in Figure 1) were conducted. 13 cone penetration tests were done as well (see data in Figure 1). 


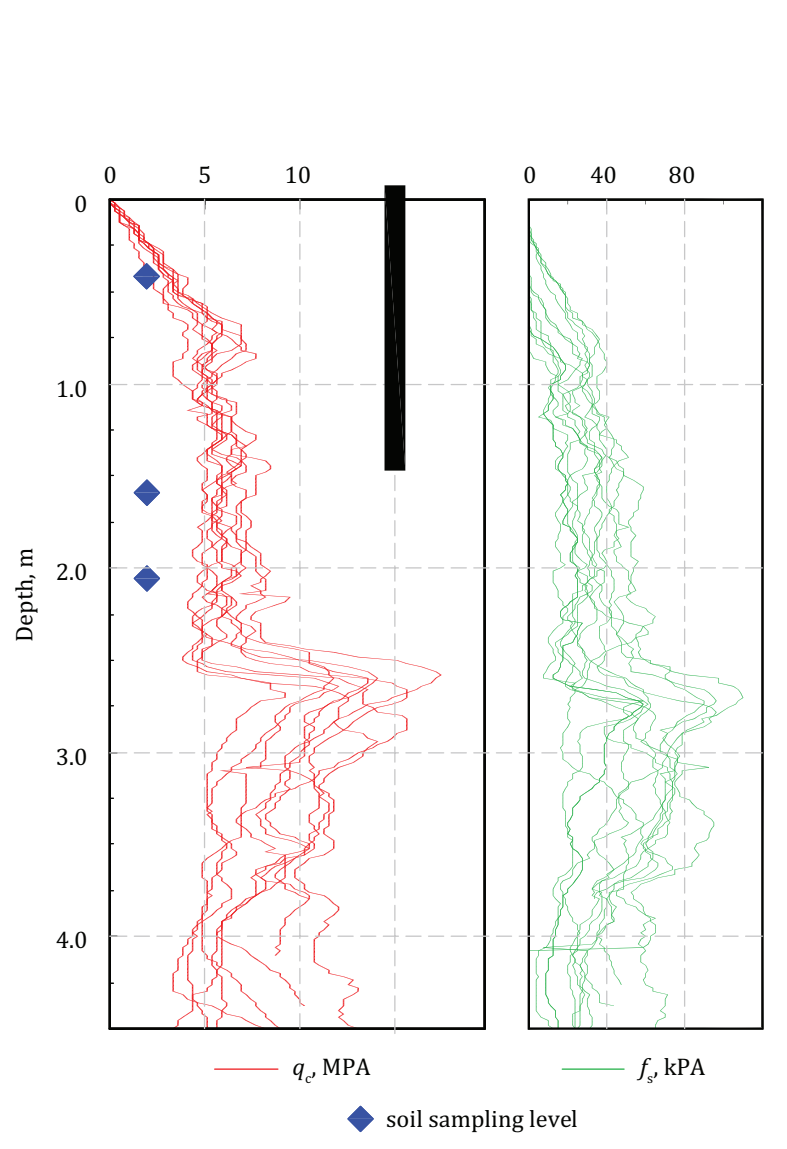

Vaidas Martinkus,

Figure 1. Cone penetration data of the created sand deposit (based on Norkus \& Martinkus, 2019)

A steel displacement pile prototype was constructed for analyzing the ground base and shaft resistance evolution of a low slenderness (end bearing) short displacement pile (SDP). The pile base and side surfaces were divided to certain sub-surfaces with the aim to investigate specifics of the pile base and skin resistance evolution at different stages of loading. Pile base surface was divided into internal surface of the circle with the radius of $105 \mathrm{~mm}$ and the remaining outer ring shape surface. Pile side surface was divided into the lower part (similar to pile radius, where resistance strongly correlates with base resistance) of height $295 \mathrm{~mm}$ and the remaining upper part. Structural dimensions of the prototype were conditioned by dimensions of instrumentation installed inside of the pile and the capability of loading set-up when loading the displacement pile group (Norkus \& Martinkus, 2019). The ground total resistance of the pile in terms of concentrated resultant forces is obtained by integrating the relevant contact stress distribution on the pile base and side surfaces mentioned above. The prototype 
Table 1. Physical and mechanical properties of sand deposit (based on Norkus \& Martinkus, 2019)

\begin{tabular}{|c|c|c|}
\hline Soil parameter & Magnitude & Unit \\
\hline Density $\rho$ & 1.64 & $\mathrm{~g} / \mathrm{cm}^{3}$ \\
\hline Water content $w$ & 4.38 & $\%$ \\
\hline Sand particle density $\rho_{\mathrm{s}}$ & 2.65 & $\mathrm{~g} / \mathrm{cm}^{3}$ \\
\hline Mean particle size $d_{50}$ & 0.33 & $\mathrm{~mm}$ \\
\hline Initial void ratio $e_{0}$ & 0.69 & - \\
\hline Maximum void ratio $e_{\max }$ & 1.65 & - \\
\hline Minimum void ratio $e_{\min }$ & 0.44 & - \\
\hline Relative density $D_{r}$ & 0.79 & - \\
\hline Friction angle at critical state $\varphi_{c s}^{\prime}$ & 30.5 & $\circ$ \\
\hline Peak friction angle $\varphi_{p}^{\prime}$ & $30.5-51.0$ & $\circ$ \\
\hline Dilatation angle $\psi_{p}^{\prime}$ & $0-26$ & $\circ$ \\
\hline Cohesion $c^{\prime}$ & 0 & $\mathrm{kPa}$ \\
\hline Oedometer coefficient of compressibility $C_{c}$ & 0.069 & - \\
\hline Dynamic deformation modulus $E_{\mathrm{d}}$ & 22.90 & $\mathrm{MPa}$ \\
\hline
\end{tabular}

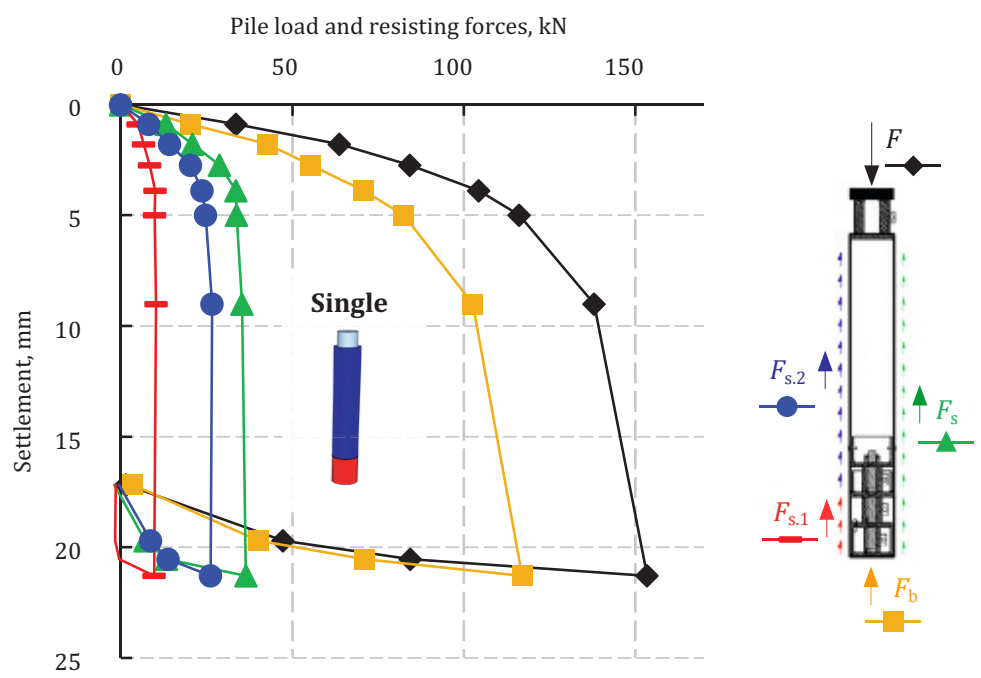

Figure 2. Pile settlement $s$ vs base $F_{\mathrm{bi}}$ and shaft $F_{\mathrm{si}}$ resisting forces (based on Norkus \& Martinkus, 2019) 


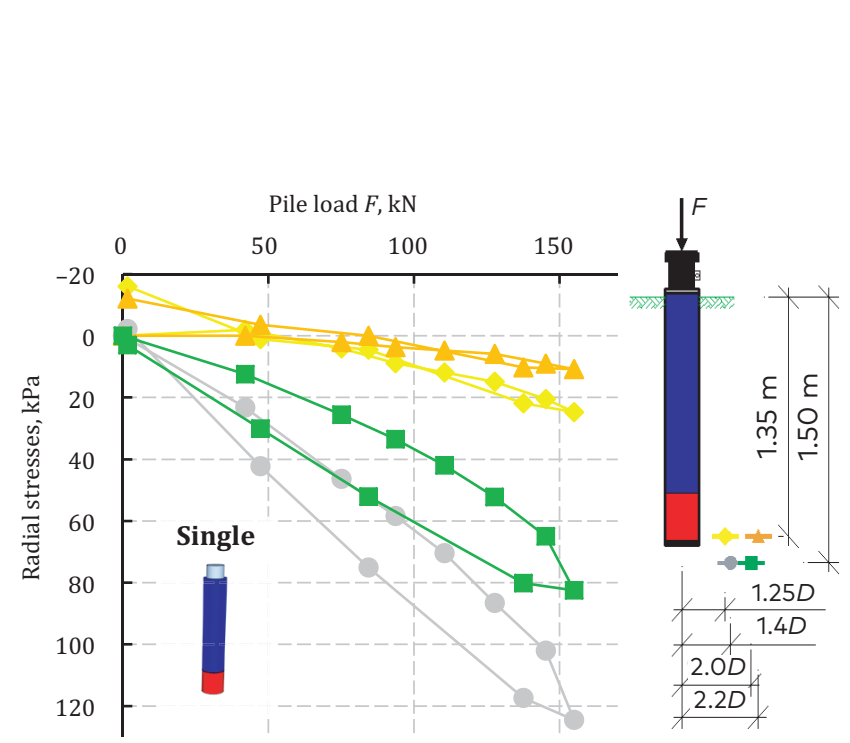

Vaidas Martinkus, Arnoldas Norkus,

Numerical Modelling of Displacement

Pile Resistance

in Sand Ground.

Part 1: Soil Physical

Model, Calibration

of Model Parameters

Figure 3. Ground horizontal (radial) stresses vs pile load at selected points

instrumentation measured the resultant forces $F_{\mathrm{i}}$, corresponding the base $F_{\mathrm{bi}}$ and the side surfaces $F_{\mathrm{si}}$. Transformation to relevant average per surface stresses on the pile surfaces was done to determine the pile-soil contact stresses. The graph representing SDP load and ground resisting forces versus pile settlement is given in Figure 2. Distribution of vertical ground displacements and horizontal (radial) stresses versus SDP load are presented in Figures 3 and 4.

More information on the short displacement pile test program (creation of sand deposit, constructional scheme of the pile prototype,

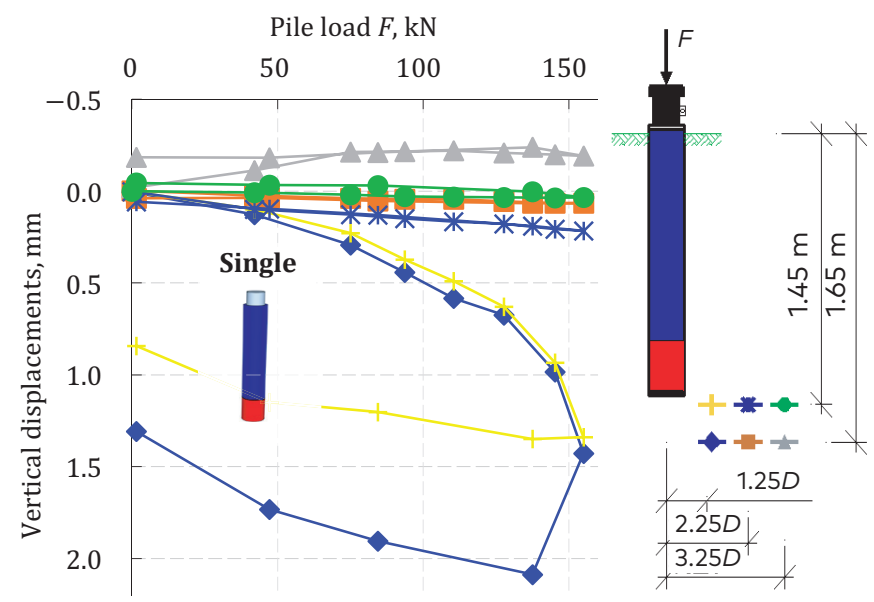

Figure 4. Ground vertical displacements vs pile load at selected points 
experimental set-up, testing equipment and pile tests) can be found in Norkus \& Martinkus (2019). Summary of the main physical and mechanical properties of the created sand deposit is given in Table 1.

Considering the evolution of ground elastic-plastic resistance (Figures 2-4), strong nonlinearity related to stress-dependency on deformation modulus and loading and unloading effects can be recognized.

\section{Selection of the physical model of soil}

The isotropic shear hardening soil model, accounting for mobilization of friction (shear hardening), can help evaluate soil behavior changes related to the development of plastic strains in the ground. The second order hyperbolic physical law of deviatoric stress versus axial strain for primary triaxial loading (Figure 5) was proposed (Schanz, Vermeer, \& Bonnier, 1999) for predicting the elastic-plastic behaviors of the soil and the contact of pile-soil. The main nonlinear physical law parameters in terms of 3 types of stiffness $E_{i}$ are illustrated in Figure 5. This hardening soil model (HSM) is implemented in FEM software Plaxis 2D (Plaxis, 2016). It allows numerical modelling of the primary loading and reloading effects of soil, hence it can also serve for evaluating the preconsolidation effect (deposit history) encountered in the process of creation of the sand deposit. Employing the processed routine soil laboratory test data, the determined values can be subsequently related to the aforementioned 3 types of soil stiffness employed by HSM (with the possibility to use the default values for them and other HSM parameters as well). Two first ones are derived from the primary deviatoric triaxial $\left(E_{50}\right)$ and oedometer $\left(E_{\text {eod }}\right)$ compression loading test. The third $\left(E_{\text {ur }}\right)$ stiffness corresponds to the elastic reloading path. The expressions for the aforementioned three stiffnesses read:

$$
\begin{gathered}
E_{50}=E_{50}^{\mathrm{ref}}\left(\frac{\sigma_{3}+c^{\prime} \cot \varphi_{\mathrm{p}}^{\prime}}{\sigma^{\mathrm{ref}}+c^{\prime} \cot \varphi_{\mathrm{p}}^{\prime}}\right)^{m}, E_{\mathrm{oed}}=E_{\mathrm{oed}}^{\mathrm{ref}}\left(\frac{\sigma_{3}+c^{\prime} \cot \varphi_{\mathrm{p}}^{\prime}}{\sigma^{\mathrm{ref}}+c^{\prime} \cot \varphi_{\mathrm{p}}^{\prime}}\right)^{m}, \\
E_{\mathrm{ur}}=E_{\mathrm{ur}}^{\mathrm{ref}}\left(\frac{\sigma_{3}+c^{\prime} \cot \varphi_{\mathrm{p}}^{\prime}}{\sigma^{\mathrm{ref}}+c^{\prime} \cot \varphi_{\mathrm{p}}^{\prime}}\right)^{m},
\end{gathered}
$$

where power $m$ is introduced for relating stress dependency against stiffness moduli. As default setting, Plaxis 2D suggests the following relationships: $E_{\text {oed }} \approx E_{50}$ and $E_{\text {ur }} \approx 3 E_{50}$. 


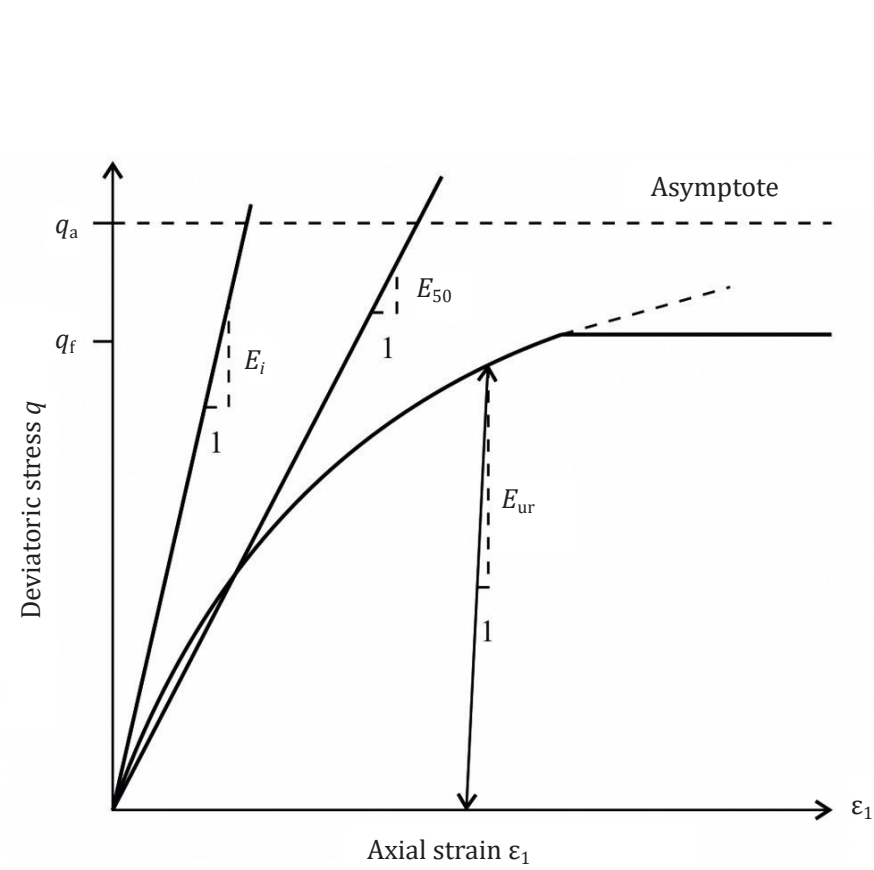

Vaidas Martinkus,

Figure 5. Hyperbolic stress-strain vs axial strain relation in primary loading for a standard drained triaxial test (according to Plaxis, 2016)

More detailed information regarding the theoretical background, selecting HSM parameters used in numerical modeling procedures of soil behavior can be found in Plaxis 2D (2016). The acknowledged efficiency of numerical modeling is widely employed by many researches. Flexibility of software Plaxis was one of the reasons for choosing it as the tool for numerical modelling of laboratory tests, firstly, for selection and calibration of the HSM parameters and, secondly, for subsequent modelling of SDP resistance test. Validation of numerical modelling results with the relevant soil laboratory and the SDP testing results served as a criterion of relevance and rationalized the use of the employed numerical modelling techniques for prediction of ground resistance evolution and determination of the magnitude of the ultimate bearing resistance (ultimate limit load) of the SDP.

\section{Numerical modelling and calibration of parameters for hardening soil model}

Application of the 2D FEM formulations in case of symmetry for discrete models of structure and loading conditions lead to significant savings of computational resources (Said, De Gennaro, \& Frank, 2019). 


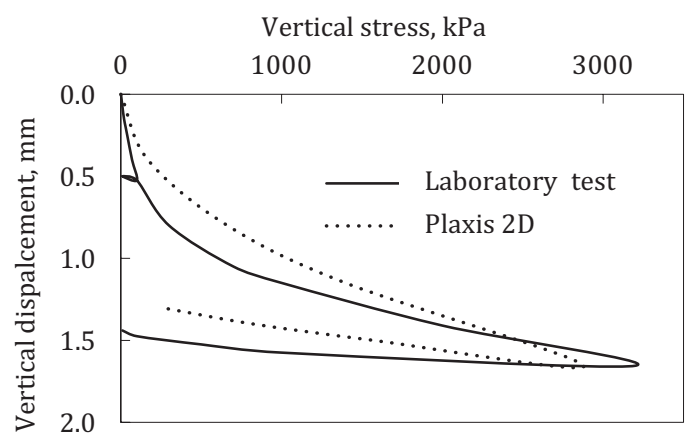

a)

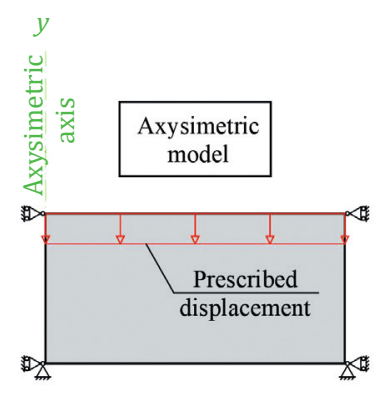

b)

Figure 6. Oedometer test: a) experimental and simulated oedometer compression graphs; $b$ ) discrete model of the oedometer test

This approach is relevant in numerical modelling of the soil laboratory and SDP loading tests, when the axisymmetric 2D discrete model FEM procedures are applied.

Stiffnesses $E_{\text {oed }}^{\text {ref }}$ and $E_{\text {ur }}^{\text {ref }}$ given in Eq. (1) were determined applying the numerical modelling and calibration of soil oedometer test graphs. The iterative procedures and back analysis method were used to reach convergence of numerical and testing results. Secant stiffness given in Eq. (1) was determined using analogous procedures for the triaxial tests, employing friction angles $\varphi_{c s}^{\prime}=\varphi_{p}^{\prime}=30.5$. The back analysis for numerical modelling of the oedometer and triaxial tests was done using

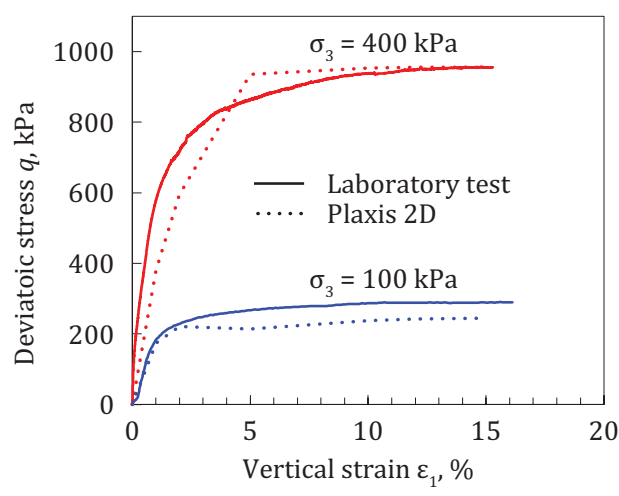

a)

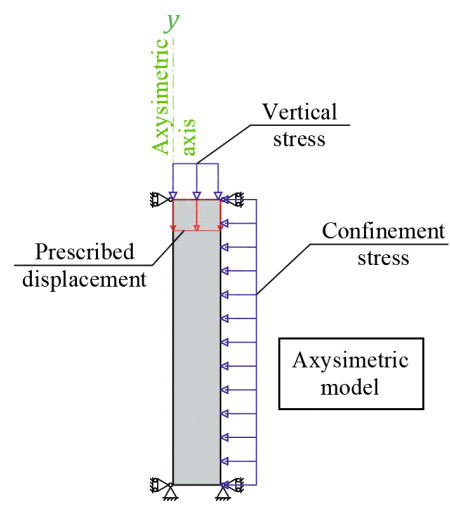

b)

Figure 7. Triaxial test: a) experimental and simulated triaxial loading graphs; b) discrete model of the triaxial test 

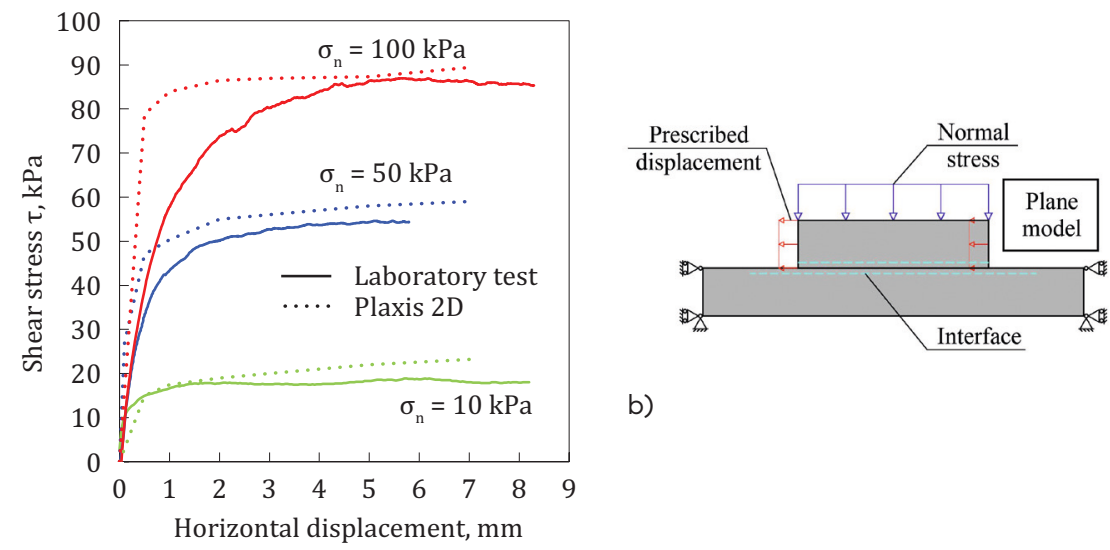

Numerical Modelling of Displacement

Pile Resistance in Sand Ground. Part 1: Soil Physical Model, Calibration of Model Parameters

b)

a)

Figure 8. Direct shear test: a) experimental and simulated loading graphs;

b) discrete model of the direct shear test

Table 2. HSM parameters

\begin{tabular}{|c|c|c|c|}
\hline Soil and HSM parameters & Magnitude & Unit & Notes \\
\hline Density $\rho$ & 1.64 & $\mathrm{~g} / \mathrm{cm}^{3}$ & - \\
\hline Initial void ratio $e_{0}$ & 0.69 & - & - \\
\hline Maximum void ratio $e_{\max }$ & 1.65 & - & $\begin{array}{l}\text { Critical density parameter (dilatancy } \\
\text { cut-off for HSM by Plaxis) }\end{array}$ \\
\hline Minimum void ratio $e_{\min }$ & 0.44 & - & - \\
\hline $\begin{array}{l}\text { Friction angle at critical } \\
\text { state } \varphi_{c s}^{\prime}\end{array}$ & 30.5 & $\circ$ & - \\
\hline Peak friction angle $\varphi_{p}^{\prime}$ & $30.5-51.0$ & $\circ$ & $\begin{array}{l}\text { To be set for soil layers of discrete } \\
\text { ground model }\end{array}$ \\
\hline Dilatation angle $\psi_{p}^{\prime}$ & $0-26$ & $\circ$ & $\begin{array}{l}\text { To be set for soil layers of discrete } \\
\text { ground model } \\
\text { Relation } \varphi_{p}^{\prime}=\varphi_{c s}^{\prime}+0.8 \psi_{p}^{\prime} \\
\text { applied according Bolton (1986) }\end{array}$ \\
\hline Reference cohesion $c^{\prime}$ & 0.2 & $\mathrm{kPa}$ & $\begin{array}{l}\text { Applied to avoid calculation } \\
\text { singularities [according to Said, } \\
\text { De Gennaro, \& Frank. (2009); } \\
\text { Mascarucci, Miliziano, Mandolini } \\
(2013,2016) \text { ] }\end{array}$ \\
\hline Reference stress & 2000 & $\mathrm{kPa}$ & - \\
\hline Oedometer loading stiffness & 125000 & $\mathrm{kPa}$ & Conforms to default Plaxis setting \\
\hline
\end{tabular}




\begin{tabular}{lccl}
\hline \multicolumn{1}{c}{ Soil and HSM parameters } & Magnitude & Unit & \\
\hline Triaxial loading stiffness & 125000 & $\mathrm{kPa}$ & Conforms to default Plaxis setting \\
\hline Triaxial unloading stiffness & 375000 & $\mathrm{kPa}$ & Default Plaxis setting \\
\hline $\begin{array}{l}\text { Power for stress magnitude } \\
\text { dependency on stiffness } m\end{array}$ & 0.45 & - & $\begin{array}{l}\text { According to Brinkgreve, Engin, Engin } \\
(2000)\end{array}$ \\
\hline \begin{tabular}{l} 
Poisson's ratio for reloading \\
\hline
\end{tabular}
\end{tabular}

the same power $m=0.45$ (proposed in Brinkgreve, Engin, \& Engin, 2000 ), and the same reference stress $\sigma_{\text {ref }}=2000 \mathrm{kPa}$ (the magnitude was determined via iterative procedures in order to fit the laboratory test graphs).

Graphs of the oedometer tests obtained by numerical modelling and at the laboratory are given in Figure 6. Numerical modelling and laboratory triaxial tests graphs are given in Figure 7.

Numerical modelling of direct shear tests was also performed. The HSM model was used for calibration of the interface elements by employing variable $\varphi_{\mathrm{p}}^{\prime}$ related to the normal stress magnitude, applied to a shearing surface. Results of numerical modelling and laboratory direct shear tests are given in Figure 8.

The main parameters of the hardening soil model, including the numerically simulated and calibrated ones, which were subsequently employed for numerical modelling of ground resistance of a short displacement pile, are given in Table 2 .

\section{Conclusions}

Test program for resistance analysis of the short displacement pile prototype has been realized. Creation of the sand deposit with stable properties per volume in the laboratory pit, subsequent cone penetration tests and laboratory tests with deposit samples for determining the initial physical and mechanical properties of the deposit were performed at the first stage of the test program. Installation of the displacement pile prototype, measurements of ground resistance during loading were performed at the second stage of the test program. The analysis of tests results demonstrated strong non-linearity of pile resistance and served for selecting the hardening soil model and Plaxis 2D software for modelling laboratory tests and displacement pile resistance. The 
numerical modelling of the oedometer and triaxial tests simulations showed good agreement with laboratory test graphs and the processed parameters: oedometer loading stiffness and triaxial loading stiffness. Calibration of these stiffnesses was performed applying 1) the power $m$ magnitude, recommended for sands and 2) calibrated reference stress magnitude, chosen via the iterative procedures in order to fit the laboratory test graphs. Numerical modelling of the direct shear test was required for calibrating the interface parameters of the contact soilpile for sand layers of the discrete ground model. Based on the results obtained via the iterative procedures and applied back analysis method, the following conclusions can be made.

1. The hardening soil model realized via Plaxis 2D and its calibrated parameters can be employed for numerical modelling of the soil behavior, as numerical results demonstrated good agreement with laboratory test results.

2. The hardening soil model and its calibrated soil parameters may by subsequently employed for 1) creating a discrete model for displacement pile testing; 2) evaluating the residual effects in the ground, accumulated during pile installation, and determining the evolution of the displacement pile resistance versus the applied vertical load.

\section{REFERENCES}

Basile, F. (2015). Non-Linear Analysis of Vertically Loaded Piled Rafts. Computers and Geotechnics, 63, 73-82. https://doi.org/10.1016/j.compgeo.2014.08.011

Bolton, M. D. (1986). The Strength and Dilatancy of Sands, Geotechnique, 36(1), 65-78. https://doi.org/10.1680/geot.1986.36.1.65

Brinkgreve, R. B., Engin. E., \& Engin, H. K. (2000). Validation of Empirical Formulas to Derive Models for Sands. In T. Benz, S. Nordal (Eds.), Numerical Methods in Geotechnical Engineering (pp. 153-158). London: CRC Press. https://doi.org/10.1201/b10551-27

El-Garhy, B., Galil, A. B., \& Mari, M. (2018). Analysis of Flexible Raft Resting on Soft Soil Improved by Granular Piles Considering Soil Shear Interaction. Computers and Geotechnics, 94, 169-183. https://doi.org/10.1016/j.compgeo.2017.09.007

Fleming, K., Weltman, A., Randolph, M., \& Elson, K. (2009). Piling engineering. London: Taylor \& Francis. https://doi.org/10.1201/b22272

Hewlet, W. J., \& Randolph, M. F. (1988). Analysis of Piled Embankments. Ground Engineering, 12-18.

Imseeh, W. H., \& Alshibli, K. A. (2018). 3D Finite Element Modelling of Force Transmission and Particle Fracture of Sand. Computers and Geotechnics, 94, 183-195. https://doi.org/10.1016/j.compgeo.2017.09.008
Numerical Modelling of Displacement

Pile Resistance in Sand Ground. Part 1: Soil Physical Model, Calibration of Model Parameters 
Jardine, F. M., Chow, W. C., Overy, R. F., \& Standing, J. R. (2005). ICP Design Methods for Driven Piles in Sands and Clays. London: Thomas Telford. https://doi.org/10.1680/idmfdpisac.32729

Lehane, B. M., Schneider, J. A., \& Xu, X. (2005). The UWA-05 Method for Prediction of Axial Capacity of Driven Piles in Sand. In Frontiers in Offshore Geotechnics. Perth: The University of Western Australia (UWA). https://doi.org/10.1201/noe0415390637.ch76

Love, J., \& Milligan, G. (2003). Design Methods for Basically Reinforced Pile-Supported Embankments Over Soft Ground. Ground Engineering, Mar., 39-43.

Mascarucci, Y., Miliziano, S., \& Mandolini, A. (2013). Effects of Residua Stresses on Shaft Friction of Bored Cast in Situ Piles in Sand. Journal of Geo-Engineering Sciences, 1(1), 37-51. https://doi.org/10.3233/jgs-13009

Mascarucci, Y., Miliziano, S., \& Mandolini, A. (2016). 3M Analytical Method: Evaluation of Shaft Friction of Bored Piles in Sands. Journal of Geotechnical and Geoenvironmental Engineering, 142(3). https://doi.org/10.1061/(ASCE)GT.1943-5606.0001392

Norkus, A., \& Martinkus, V. (2019). Experimental Study on Bearing Resistance of Short Displacement Pile Groups in Dense Sands. Journal of Civil Engineering and management, 25(6), 551-558. https://doi.org/10.3846/jcem.2019.10403

Plaxis. (2016). PLAXIS 2D Foundation Reference Manual.

Raithel, M., Kirchner, A., \& Kempfert, H. G. (2008). German Recommendations for Reinforced Embankments on Pile-Similar Elements. In 4th Asian Regional Conference on Geosynthetics (vol. 1, pp. 697-702). China, Shanghai.

Said, I., De Genaro, V., \& Frank, R. (2009). Axisymmetric Finite Element Analysis of Pile Loading Tests. Computers and Geotechnics 36(1-2), 6-19. https://doi.org/10.1016/j.compgeo.2008.02.011

Schanz, T., Vermeer, P. A., \& Bonnier, P. G. (1999). The Hardening Soil Model: Formulation and Verification. In Proceedings of Beyond 2000 in Computational Geotechnics - 10 Years of Plaxis (pp. 281-298).

Schmertmann, J. H. (1978). Guidelines for Cone Test, Performance and Design. U.S. Federal Highway Administration FHWATS-78209.

Unsever, Y. S, Matsumoto, T., \& Ozkan, M. Y. (2015). Numerical Analyses of Load Tests on Model Foundations in Dry Sand. Computers and Geotechnics, 63, 255-266. 